\title{
Reducing infections through nanotechnology and nanoparticles
}

\author{
Erik Taylor' \\ Thomas J Webster ${ }^{1,2}$ \\ 'School of Engineering, ${ }^{2}$ Department \\ of Orthopedics, Brown University, \\ Providence, RI, USA
}

This article was published in the following Dove Press journal:

International Journal of Nanomedicine

I2 July 20 I I

Number of times this article has been viewed
Correspondence: Thomas JWebster School of Engineering and Department of Orthopedics, Brown University, Providence, RI 02917, USA

$\mathrm{Tel}+$ I 4018632318

Fax + I 4018639107

Email thomas_webster@brown.edu

\begin{abstract}
The expansion of bacterial antibiotic resistance is a growing problem today. When medical devices are inserted into the body, it becomes especially difficult for the body to clear robustly adherent antibiotic-resistant biofilm infections. In addition, concerns about the spread of bacterial genetic tolerance to antibiotics, such as that found in multiple drug-resistant Staphylococcus aureus (MRSA), have significantly increased of late. As a growing direction in biomaterial design, nanomaterials (materials with at least one dimension less than $100 \mathrm{~nm}$ ) may potentially prevent bacterial functions that lead to infections. As a first step in this direction, various nanoparticles have been explored for improving bacteria and biofilm penetration, generating reactive oxygen species, and killing bacteria, potentially providing a novel method for fighting infections that is nondrug related. This review article will first examine in detail the mechanisms and applications of some of these nanoparticles, then follow with some recent material designs utilizing nanotechnology that are centered on fighting medical device infections.
\end{abstract}

Keywords: nanomaterials, medical device infection, antibacterial, antibiotic resistance, nanoparticle, biofilms

\section{Bacterial biofilms and antibiotic-resistant infection}

Medical device infections can be frequent and costly depending on the device location and the duration of use. Yet the benefits from these devices outweigh this low probability detriment and therefore continue to be used clinically. For example, peripheral or central intravenous catheters (CVCs) resulting in bloodstream infections (BSI) occur in about 4-5 out of every 1000 CVC devices inserted, ${ }^{1,2}$ with an attributed cost per infection estimated at US\$34,508-\$56,000, ${ }^{3,4}$ and the annual cost of caring for patients with CVC-associated BSIs ranges from \$296 million to \$2.3 billion. ${ }^{5}$ However, CVCs are necessary for the delivery of fluids and medication or for monitoring patient health (such as through the drawing of blood or monitoring of blood pressure).

In addition to transcutaneous extracorporeal devices or other medical devices that are constantly exposed to the nonsterile environment outside the body, implanted devices are also susceptible to infections, resulting in implant failure. For example, prosthetic joint replacements are permanently implanted to alleviate pain, promote mobility, and improve the quality of life, but such implantations also suffer from the risk of infection, which occurs in about $1 \%-1.5 \%$ of all total hip and knee arthroplasties (THAs and TKAs, respectively) in the USA. ${ }^{6}$ Although the chance of infection is rare in these procedures, the problem is significant, as periprosthetic implant infections, which are also known as septic failures and cost about US\$70,000 per episode, are the most common cause of revision surgery in all TKAs $(25 \%)$, the third most 
common cause in all THAs (15\%), and the most common reason for removal of all TKAs (79\%) and THAs (74\%). ${ }^{6-8}$ Prosthesis device infections are some of the most striking medical device infections due to the widespread use of prosthesis devices, but other implanted medical devices, such as intrauterine devices, mechanical heart valves, pacemakers, tympanostomy tubes, and voice prostheses, can similarly suffer from infection, and could benefit from new therapies beyond antibiotics. ${ }^{9}$

When a device must be removed to eradicate an infection, it is often because bacteria have produced a sticky biofilm matrix, forming a strong adhesion to the device surface. Immediately after binding to a surface, bacteria begin to secrete and collect proteins, polysaccharides, and DNA to formulate a biofilm. ${ }^{10,11}$ An outline of biofilm pathogenicity demonstrating macroscopic biofilm dissemination, a representative micrograph of bacteria embedded in a biofilm matrix, and a schematic of biofilm formation is shown in Figure 1. Biofilm bacteria are resistant to antibiotic treatment, therefore infection is recalcitrant without prolonged treatment or removal of the device. ${ }^{12}$ After biofilm formation occurs, the simplest way to treat the infection is to remove the infected surface, which contains the sticky biofilm matrix. Yet, with permanent fixtures, such as prosthetic devices, device removal can be difficult or debilitating to the patient, especially if they are very young or old. In addition, chronic infections that do not respond to antibiotic treatment and require removal of adjacent devitalized bone and soft tissue, and may also require plastic surgery. ${ }^{13}$

Bacterial genetic tolerance to antibiotics is another current problem in the treatment of medical device-related infections. In particular, multiple drug-resistant Staphylococcus aureus (MRSA) have caused great concern about the spread of antibiotic-resistant bacteria, with implant infections (including grafts and implantable medical devices) being the third most common cause of potential MRSA infections leading to hospitalization between 1999 and 2005. ${ }^{14}$ More recent in-depth analysis found that $56 \%$ of all device-associated infections with $S$. aureus were reported as MRSA between 2006 and 2007..$^{15}$ The International Nosocomial Infection Control Consortium (INNIC) also reported that of all S. aureus isolated, $84.1 \%$ contained MRSA internationally (with the most recent data from 2008). ${ }^{16}$ Of equal concern, MRSA infections are costing the health care system

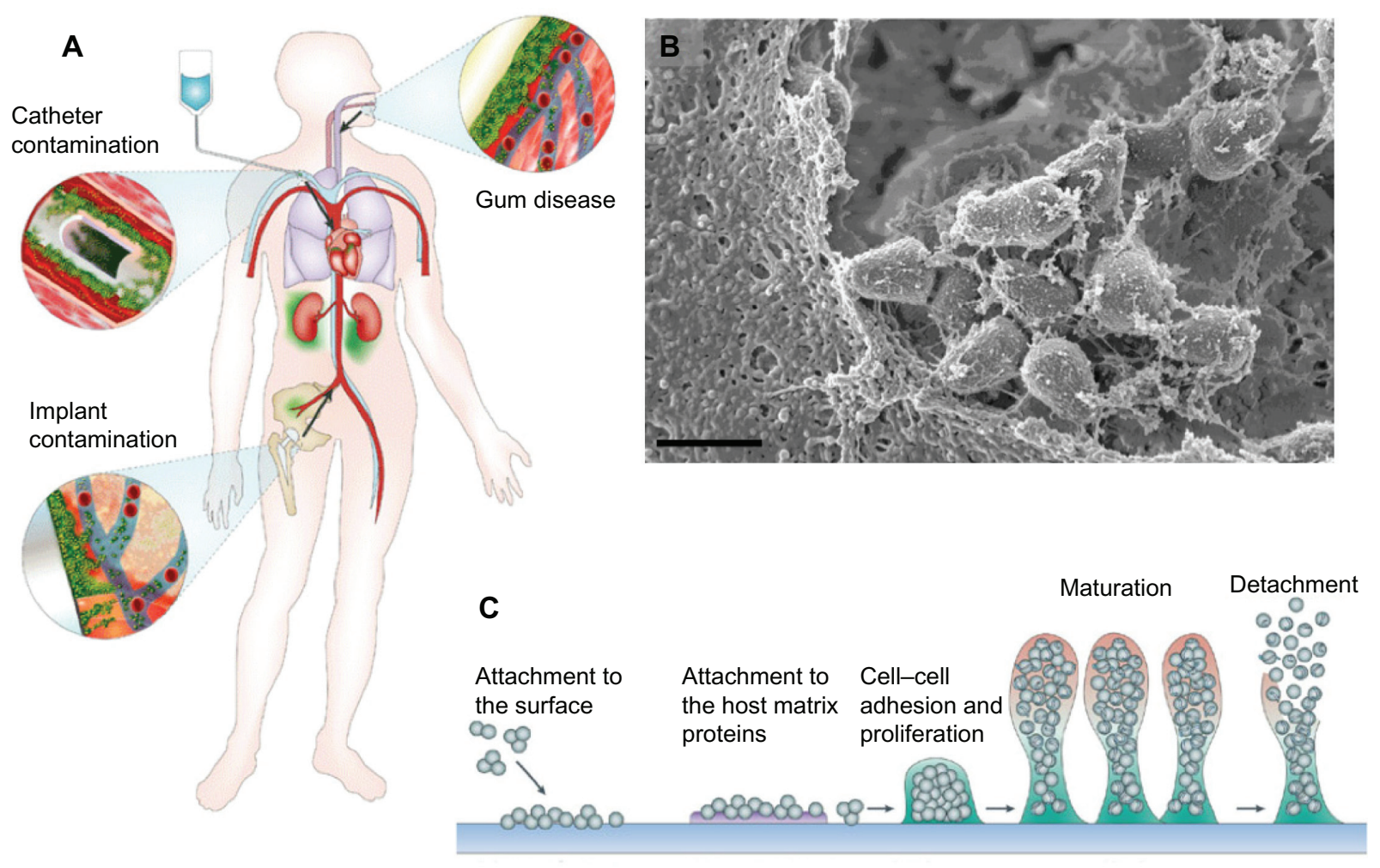

Figure I Biofilm pathogenicity in humans is mediated by dissemination and biofilm matrix formation. (A) Possible routes of biofilm dissemination around the body originating from sites such as gum disease, catheter, or implant contamination. ${ }^{12}$ (B) Scanning electron micrographs (SEM) of biofilm matrix, offering protection of resident bacteria from eradication, imaged from a clinical endotracheal tube identified as Streptococcus pneumonia. Scale bar shown is I $\mu \mathrm{m}$. (C) Schematic of biofilm-mediated device-related infection, starting with bacterial attachment to a device or adsorbed host proteins, leading to biopolymer mediated cell-cell adhesion, maturation, and eventual detachment leading to the spread of infection. ${ }^{66}$

Note: $\mathbf{A}$ is reproduced from Hall-Stoodley et $\mathrm{al}^{12}$ and $\mathbf{C}$ is reproduced from Otto ${ }^{66}$ with permission from the publishers. 
up to an estimated US\$9.7 billion excess costs, and the percentage of infections with MRSA are expected to continue to increase. ${ }^{14,16}$

In addition to MRSA, concerns are growing about all bacterial tolerance to antibiotics more generally. One such example is the growing bacterial tolerance to the drug long considered the antibiotic of last resort, vancomycin. In fact, clinically relevant resistance to glycopeptides vancomycin and teicoplanin were reported in vancomycin-resistant enterococci (VRE) as early as 1992, through the plasmidborne transferable gene VanA. ${ }^{17,18}$ Glycopeptide tolerance in other bacteria, such as $S$. aureus, through VanA gene transfer has also been reported, although is clinically rare. ${ }^{18}$

In addition to bacteria, fungi are also becoming tolerant to antibiotic treatments, either through biofilm formation or genetic tolerance. Candida albicans is the most frequent of these human pathogens, with various strains isolated from the clinical setting exhibiting resistance to antifungals, such as triazole, ${ }^{19}$ or developing antibiotic-resistant biofilms, ${ }^{20}$ posing a significant threat to the infected individual through increased resistance to antifungal treatments. Other pathogenic Candida species are also being reported with multidrug tolerances, such as Candida krusei. ${ }^{21}$

The use of nanoparticles is a growing new approach against biofilm-mediated, drug-resistant, and devicecentered infections. For anti-infection applications, various nanomaterials are being developed, such as nanoparticles and nanotubes, for direct use as biomedical devices; such nanomaterials can be used alone, incorporated onto surfaces, into composites, or as components in sensors such as zinc oxide $(\mathrm{ZnO})$ nanoparticles, gold nanoparticles, carbon nanotubes, and iron oxide nanoparticles, respectively, shown in Figure 2A-E. These examples, and others, will be further reviewed here to understand their antibacterial activity and potential applications.

\section{Bacterial response and systemic applications of nanoparticles}

Nanoparticles, which consist of metals such as silver and metal oxides, may be promising agents for antibacterial applications. Additionally, nanoparticles may also have some general mechanism of toxicity toward bacteria that mammalian cells do not have. Nanoparticles bind to bacterial cell walls causing membrane disruption through direct interactions or through free radical production. ${ }^{22}$ Mammalian cells are able to phagocytose nanoparticles, and can subsequently degrade these particles by lysozomal fusion, ${ }^{23}$ reducing toxicity and free radical damage. This may allow for the selectivity of the same nanoparticle to promote tissue-forming cell functions, while also inhibiting bacterial functions that lead to infection.

The antibacterial activity of silver has long been known, but by decreasing particle size into the nanometer range, surface area is increased, and the antibacterial activity of the material is increased. ${ }^{24}$ The use of colloidal silver for minimizing infection has been investigated for over 50 years, but with recent advances in chemical, biological, and material characterization techniques, silver is being more widely adopted in the medical community. By binding with DNA, with enzymes that control respiration and other critical cell functions, or with chemical functionality or receptors on the cell membrane, nanoparticles of silver have been very effective against many otherwise intractable infectious organisms (such as MRSA and other antibiotic-resistant microorganisms). ${ }^{25}$

Metal oxide nanoparticles are also under investigation for their inherent antimicrobial properties, which are enhanced, or may only exist, when the materials are in the nanometer size and in relation to surface area. For example, size-dependent antibacterial properties of magnesium oxide nanoparticles have been observed against Escherichia coli and $S$. aureus, where it was shown that for $23,18,15,11$, and $8 \mathrm{~nm}$ particles, the smallest $8 \mathrm{~nm}$ particles decreased bacteria growth the most. ${ }^{26}$ Dose-dependent antimicrobial properties have also been observed for iron oxide and may only exist when it is formulated into nanometer, rather than micron, particles. ${ }^{27}$ Greater $\mathrm{ZnO}$ antibacterial activity has been observed as particle size decreases into the nanometer level in relation to surface area. ${ }^{28}$ Using nitrogen gas $\left(\mathrm{N}_{2}\right)$ isotherms and the Brunauer-Emmett-Teller equation in the relative pressure range $\left(P / P_{\mathrm{o}}\right)$ of $0.05-0.30$, researchers have found a direct correlation between surface area, particle size (calculated from surface area), and antibacterial activity of $\mathrm{ZnO}$, with activity ranging from $\sim 5 \%-90 \%$ decreased bacteria viability among surface areas of 90.4-3.49 m²/g (corresponding to calculated $\mathrm{ZnO}$ particle sizes from 12 to $307 \mathrm{~nm}) .{ }^{28}$ Furthermore, the authors found that the 4-7 mM $\mathrm{ZnO}$ colloidal suspension with the highest surface area $\left(90.4 \mathrm{~m}^{2} / \mathrm{g}\right.$ ) inhibited $95 \%$ of MRSA, Enterococcus faecalis, a high-biofilm-producing strain Staphylococcus epidermidis, and various other clinically relevant pathogen growths. ${ }^{28}$ Despite such positive results, the $\mathrm{ZnO}$ suspension was least effective against Salmonella typhimurium, inhibiting only $50 \%$ of growth $;^{28}$ because this is still a relevant pathogen (there was, for example, a peanut butter-related outbreak in $2009^{29}$ ), further studies should focus on the mechanism of $\mathrm{ZnO}$ nanoparticle resistance in this pathogen. 

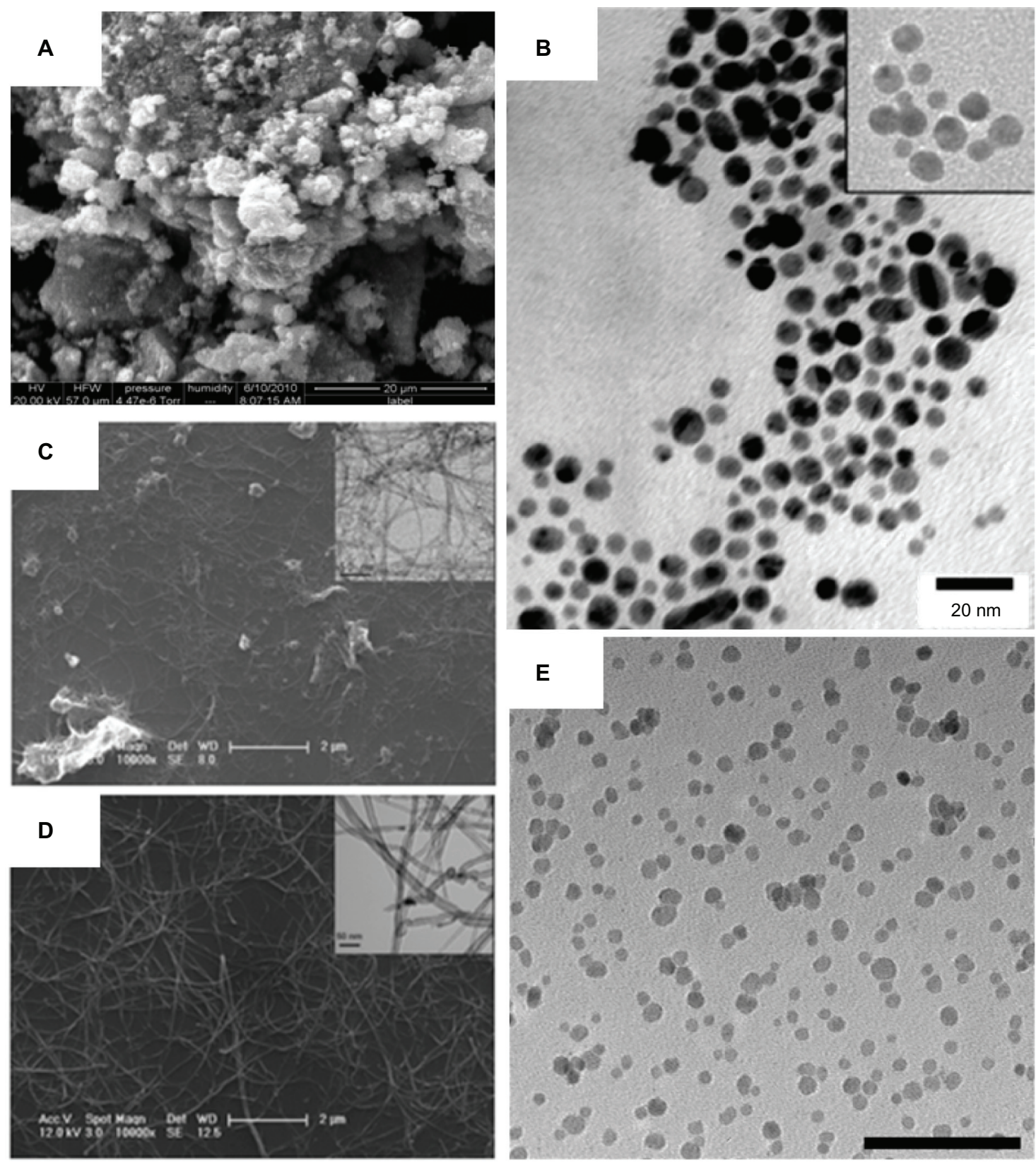

Figure 2 Various nanomaterials are being studied for emergent antimicrobial properties and are being used for the design of the next generation of therapeutics and biomaterials. Zinc oxide nanoparticles (shown in A) have a high surface area and a particle size of about $12 \mathrm{~nm}$, demonstrating antibacterial activity (scanning electron micrograph; scale bar: $20 \mu \mathrm{m}$ ). Vancomycin-coated gold nanoparticles (shown in B), with an inset at the minimum inhibitory concentration, are able to overcome resistance in several strains of vancomycin-resistant bacteria (transmission electron micrograph; scale bar: $20 \mathrm{~nm}$ ). ${ }^{37}$ The enhanced antimicrobial properties of single-walled carbon nanotubes compared with larger diameter multiwalled carbon nanotubes (as shown in $\mathbf{C}$ and $\mathbf{D}$, respectively) could be used as conductive biomaterials, in situ sensors, or tissue engineering scaffolds (scale bars: $2 \mu \mathrm{m}$ and $50 \mathrm{~nm}$, as shown in inset). ${ }^{54}$ Superparamagnetic iron oxide nanoparticles (shown in E; scale bar: $100 \mathrm{~nm}$ ) with antimicrobial properties are being explored for controlled delivery to infection sites.

Notes: A is reprinted with permission from Raghupathi KR, Koodali RT, Manna AC. Size-dependent bacterial growth inhibition and mechanism of antibacterial activity of zinc oxide nanoparticles. Langmuir. 20I I;27(7):4020-4028. Copyright 20I I American Chemical Society. B is reprinted with permission from Gu H, Ho PL, Tong E, Wang L, Xu B. Presenting vancomycin on nanoparticles to enhance antimicrobial activities. Nano Letters. 2003;3(9): I26I-1263. Copyright 2003 American Chemical Society. C and D are reprinted with permission from Kang S, Mauter MS, Elimelech M. Microbial cytotoxicity of carbon-based nanomaterials: implications for river water and wastewater effluent. Environ Sci Technol. 2009;43(7):2648-2653. Copyright 2009 American Chemical Society.

These studies and others determined that nanoparticle antibacterial activity could be mediated by increasing reactive oxygen species (ROS) production, ${ }^{30,31}$ as a result of the use of metal oxide nanoparticles due to metal ion release (which is related to surface area) or through their interaction with ultraviolet (UV) light (which also depends on particle size). ${ }^{31,32}$ For example, iron ions generate oxygen free radicals by converting hydrogen peroxide $\left(\mathrm{H}_{2} \mathrm{O}_{2}\right)$ to the more reactive hydroxyl radical via the Fenton reaction. ${ }^{32}$ Hydroxyl radicals generated by these iron ions 
can depolymerize polysaccharides, cause DNA strands to break, inactivate enzymes, and initiate lipid peroxidation. ${ }^{33}$ Such events would also be accelerated through the increased surface area of nanometer compared with micron particles, especially when such nanoparticles penetrate the bacteria.

A very detailed analysis of $\mathrm{ZnO}$ nanoparticle $\mathrm{ROS}$ generation was carried out recently by Lipovsky et al. ${ }^{34}$ In this study, it was found that, when using electron paramagnetic resonance coupled with the spin-trapping technique, the formation of hydroxyl radicals and singlet oxygen in water suspensions of $\mathrm{ZnO}$ nanoparticles resulted, but the possibility of superoxide anion production was ruled out. ${ }^{34}$ Moreover, the level of oxy radicals increased considerably when the suspension was irradiated with visible light at the range 400-500 nm, demonstrating the ability of nondestructive visible light (as opposed to UV light) to stimulate ROS production in $\mathrm{ZnO} .{ }^{34}$ One limitation of this study was that the possibility of $\mathrm{H}_{2} \mathrm{O}_{2}$ production by $\mathrm{ZnO}$ was not discounted, as has been previously observed in suspensions of $\mathrm{ZnO}$ as a primary mediator of antibacterial activity. ${ }^{30,35,36}$
An ideal antibacterial entity for treating infection would be delivered with high efficiency to the site of infection and selectively target bacteria over other cells; the therapeutic effectiveness of the entity should also be able to be ascertained. An appropriate target mechanism would direct the antibacterial treatment to the site of infection. Antibacterial activity would remove and inhibit those organisms relevant to infection and would be useful against all virulent strains. Finally, therapeutic feedback would provide information about the effectiveness of the treatment, location of infection, and delivery efficiency. Modular nanopharmaceutical systems are being designed to address all of these multifunctional capabilities for the ideal bacterial treatment, with the ability to mix and match appropriate functions.

One way to achieve such multifunctionality would be to tailor nanoparticles for specific applications through surface conjugation. Surface conjugation is the final chemical modification of nanoparticles, providing the opportunity to deliver drugs to the site of infection to selectively interact with (and penetrate) the biofilm and bacteria targeted. Figure 3 highlights the various ways that surface-active nanoparticles can interact

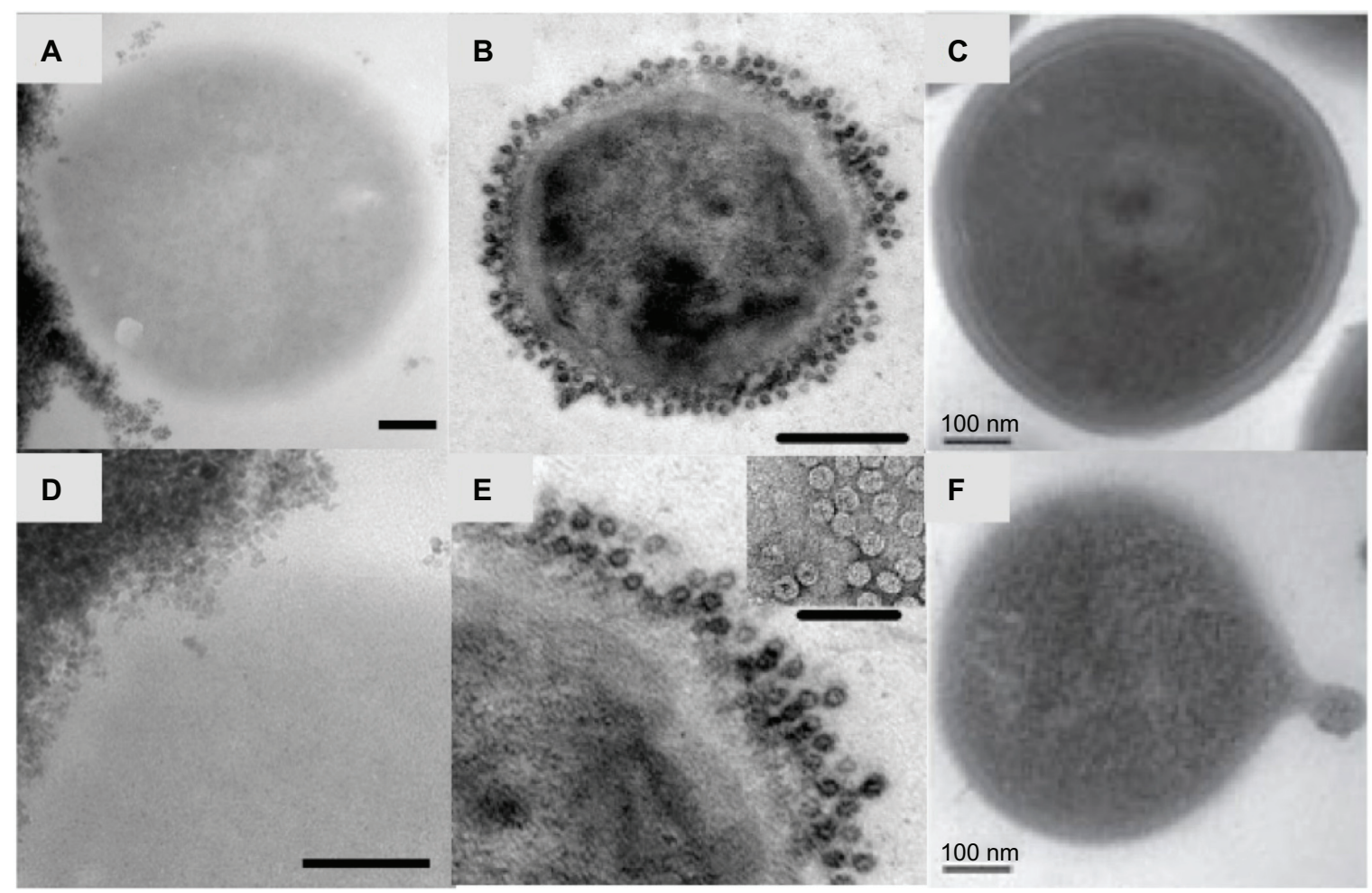

Figure 3 Transmission electron micrographs of Staphylococcus aureus bacteria interacting with nanoparticles including superparamagnetic iron oxide nanoparticles (A and D), cowpea chlorotic mottle virus (CCMV) nanoparticles (B and E), and self-assembled cationic peptide nanoparticles ( $\mathbf{C}$ and $\mathbf{F})$. Magnetic nanoparticles bind to the bacterial cell surface resulting in membrane disruption (A) and nanoparticle penetration (D) potentially used for bacterial separations. CCMV binds to a coating of protein A antibodies on S. aureus membranes through biotin-streptavidin interactions (B) without penetration (E; inset: close-up view of the coated surface) for targeting of magnetic resonance imaging contrast agents. ${ }^{40} \mathrm{~S}$. aureus before $(\mathbf{C})$ and after $(\mathbf{F})$ membrane disruption by self-assembled cationic peptide nanoparticles, leading to a rough surface and the formation of a minicell. ${ }^{41}$

Note: Scale bars: A, C-F, $100 \mathrm{~nm}$; B, $200 \mathrm{~nm}$. B and E are reprinted from Chemistry and Biology, I4/4, Suci PA, Berglund DL, Liepold L, et al, High-density targeting of a viral multifunctional nanoplatform to a pathogenic, biofilm-forming bacterium, 387-398, 2007, with permission from Elsevier. $\mathbf{C}$ and $\mathbf{F}$ are reproduced from Liu et al with permission from the publisher. ${ }^{41}$ 
with bacteria ( $S$. aureus is shown here as an example) toward penetrating, targeting, and disrupting bacteria. Nanoparticle conjugation can also improve drug efficacy by increasing the number of active drug loading sites (through conjugation of multiple selected agents onto one nanoparticle).

It has been shown that antibiotic resistance can be overcome in vancomycin-resistant bacteria using gold nanoparticles coated with vancomycin (ie, gold functionalized with vancomycin [Au@Van]; shown in Figure 2B). ${ }^{37,38}$ Vancomycin is an inhibitor of cell-wall synthesis, normally binding to D-alanine repeat units (D-ala-D-ala) on the bacterial cell surface, but in vancomycin-resistant bacteria, such as VRE, modifications of terminal cell-surface peptides (such as to D-lactate) lower antibiotic activity. In a study by Gu et al,Au@Van with activity against VRE was prepared through the interaction of synthetic gold nanoparticles with bis(vancomycin) cystamide, through gold and sulfur interactions lowering the minimum inhibitory concentration (MIC) of resistant bacteria to between 2 and $4 \mu \mathrm{g} / \mathrm{mL} .{ }^{37}$ It was hypothesized that antibacterial activity increased as a consequence of close contact among vancomycin molecules ( $\sim 31$ per nanoparticle), changing the binding properties in a phenomenon called "polyvalent inhibition." ${ }^{39}$ In a more recent study by Fayaz et al, a novel preparation of Au@Van effectively inhibited the growth of vancomycin-resistant S. aureus at an MIC of $8 \mu \mathrm{g} / \mathrm{mL}^{38}$ In this study, gold nanoparticles were synthesized biologically using the fungus Trichoderma viride and vancomycin was bound to the surface by ionic interactions, allowing the positively charged amine groups of vancomycin to interact with the negatively charged gold nanosurface. It was hypothesized that the nanoparticles bound nonspecifically to cell-surface peptides involved in cell-wall synthesis, but no further evidence of this was provided. Interestingly, both studies withAu@Van found activity against $E$. coli growth, which is normally not inhibited due to the inability of vancomycin to penetrate the gram-negative bacteria outer membrane..37,38 Fayaz et al proposed that Au@ Van penetrated the gram-negative bacteria membrane, as evidenced by pitting that was visible in the cell membrane under transmission electron microscopy. ${ }^{38}$

Selective targeting of nanoparticles to an infection site minimizes uptake by surrounding tissues and decreases exposure of nonpathogenic bacterial flora (altering the balance of natural flora that would exacerbate virulent bacterial growth). Chemical targeting is highly specific and requires identification of an epitope (such as a molecule or protein) in the bacterial biofilm for nanoparticle delivery. In particular, Suci et al found that $S$. aureus biofilm targeting could be achieved through the use of a viral nanoparticle, cowpea chlorotic mottle virus (CCMV), coated with antibodies to protein A (which is a $S$. aureus surface protein and virulence factor). ${ }^{40}$ It was found that CCMV bound to the surface of $S$. aureus in biofilms ( $\sim 30 \mu \mathrm{m}$ thick), penetrated 17.6 (standard deviation 3.3) $\mu \mathrm{m}$ during an 80-minute exposure (Figure 4A). ${ }^{40}$ The cage-like protein structure of CCMV could simultaneously be loaded with the magnetic resonance imaging (MRI) contrast agent gadolinium $(\mathrm{Gd})$ achieving a concentration of $1.8 \times 10^{5}$ Gd atoms per cell, as determined by inductively coupled plasma atomic emission spectroscopy. ${ }^{40}$

Targeting drugs across the blood-brain barrier (BBB) to fight neural tissue infection is another issue with traditional infection drug design that is currently being addressed by nanotechnology. When targeting brain infection, such as meningitis, nanoparticles may be able to cross the BBB and kill a broad spectrum of microorganisms. For example, one study by Liu et al found that self-assembled cationic peptide nanoparticles synthesized through the incorporation of a cationic peptide (composed of six arginine residues), a TAT peptide sequence
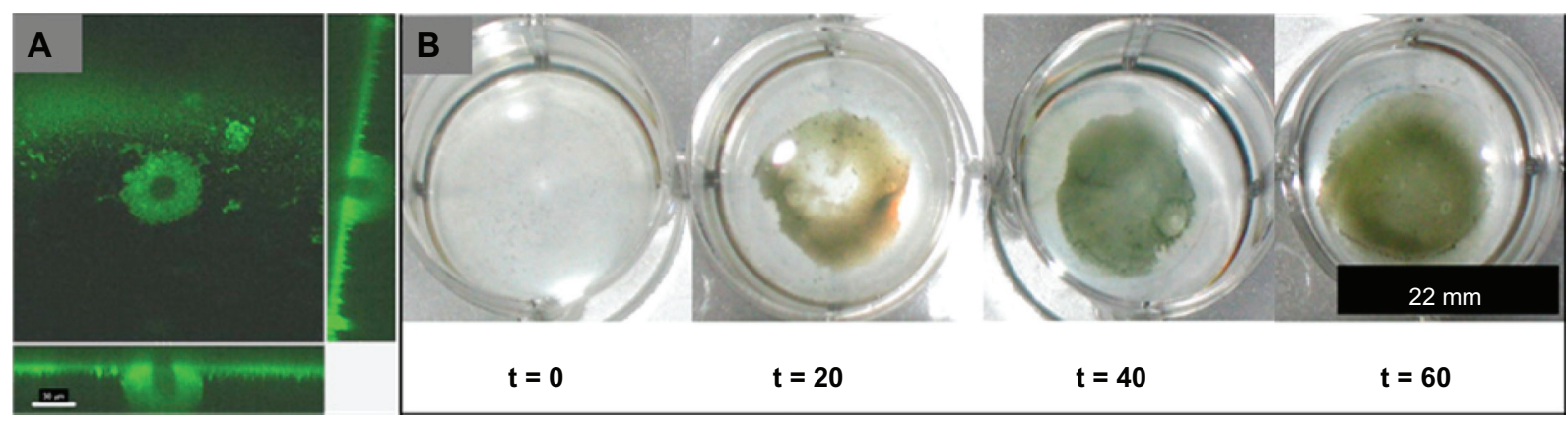

Figure 4 Staphylococcus aureus biofilm penetration by cowpea chlorotic mottle virus (CCMV) (A) and superparamagnetic iron oxide nanoparticles (SPION) (B), analyzed by confocal fluorescence microscopy and Prussian blue histology stains for iron, respectively. (A) S. aureus biofilm penetrated by a CCMV nanoplatform (green fluorescence in micrograph) demonstrating a penetration depth of $17.6 \mu \mathrm{m}$ during an 80 -minute exposure (main panel shows the top view of the biofilm, and the right and bottom panels are cross-sectional views showing CCMV penetration depth) ${ }^{40}$ (scale bar: $30 \mu \mathrm{m}$ ). (B) Bulk penetration of SPION into an S. aureus biofilm cannot be observed without magnetic field exposure for I hour (magnetic field time zero; $t=0$ ), and is enhanced through application of a magnetic field (magnetic field time 20, 40 , or 60 minutes; $t=20,40$, or 60). Note: A is reprinted from Chemistry and Biology, I4/4, Suci PA, Berglund DL, Liepold L, et al, High-density targeting of a viral multifunctional nanoplatform to a pathogenic, biofilm-forming bacterium, 387-398, 2007, with permission from Elsevier. 
(recognized by the BBB for cell-membrane translocation), and a cholesterol core were useful for fighting neural tissue infection. ${ }^{41}$ Broad antimicrobial activity was achieved, with higher efficacy in killing bacteria and fungi than many currently available antibiotics. ${ }^{41}$ Moreover, using an in vivo mouse model, it was found that the nanoparticles that targeted brain infections by crossing the BBB were equally as effective as vancomycin alone. ${ }^{41}$ This shows that, through the application of nanotechnology and self-assembly, new antimicrobial therapeutics can be designed to target brain infections without relying on drugs that bacteria may eventually develop resistance to.

Nanomaterials possessing superparamagnetic properties, such as iron oxide nanoparticles (Figure 2E), can be directed in situ using a magnetic field - potentially to the site of infection. Iron oxide nanoparticles have been used for numerous biomedical applications, such as for the separation of biomolecules from bacteria or delivery of antibiotics and drugs, with simultaneous enhancement of MRI contrast. ${ }^{42-44}$ For in vivo applications, regional magnetic targeting has been used to increase the local concentration of certain magnetic materials in one body compartment (for example, the brain or upper or lower body). A study by Chertok et al focused on improving drug uptake across the BBB using $100 \mathrm{~nm}$ superparamagnetic iron oxide nanoparticles (SPION) and a $0.4 \mathrm{~T}$ static magnetic field, where a fivefold increase in nanoparticle exposure was achieved in a brain cancer model as determined by MRI. ${ }^{45}$ It has also been demonstrated that a magnetic field can increase the uptake of magnetic nanoparticles into bacterial biofilms (Figure 4B). Using mixed methods of targeting and imaging, SPION could further improve the treatment of infections. One such method consists of detecting the location of SPION and using an externally applied magnetic field in response. For example, Oh et al used ultrasound to visualize an intravenous injection of $20 \mathrm{~nm}$ SPION and exciting results were obtained demonstrating SPION movement under focused magnetic fields. ${ }^{46}$ The introduction of ultrasound as an imaging modality that can be used to visualize SPION opens up the possibility of bedside application of feedback-controlled magnetic drug delivery for treating various infections.

\section{Nanotextured surfaces for the development of antimicrobial biomaterials}

Nanotextured surfaces that can reduce microbial adhesion, proliferation, and biofilm growth through emergent antimicrobial properties, as have been found in materials such as $\mathrm{ZnO}$, titanium dioxide $\left(\mathrm{TiO}_{2}\right)$, polymers, and carbon nanotubes, are being studied. Due to its ability to mimic the constituent properties of natural tissues, nanotechnology is being heavily investigated as a promising tool in tissue engineering and biomaterials. The incorporation of nanotechnology into tissue engineering has recently been reviewed in more detail. ${ }^{47}$ Briefly, it is believed that nanofeatured medical device surfaces enhance surface energy, increase select protein adsorption, promote protein bioactivity, and improve subsequent tissue-forming cell functions, ${ }^{47}$ while many researchers now hypothesize that this same action could simultaneously prevent bacterial colonization. ${ }^{48,49}$ This idea has been used in industry, as antimicrobial nanoparticles are incorporated into numerous paints and other materials that affect our daily lives.

Medical devices are being designed through the incorporation of carbon nanotubes (Figures 2C and D) into sensors $^{50,51}$ to serve as feedback loops to detect bacteria and release antibiotics only when needed (as has been previously shown with carbon nanotube-coated titanium, which was used, after sensing an infection, to break down a thin film of polypyrrole containing antibiotics ${ }^{52}$ ). Moreover, researchers also benefit from the potential antimicrobial properties of these nanomaterials even when not used as sensors.

For example, the antimicrobial properties of carbon nanotubes have been documented, with a dependence on carbon nanotube diameter. In a series of studies, it was found that multiwalled carbon nanotubes (MWNTs) and single-walled carbon nanotubes (SWNTs), created as mat-like surfaces, inactivated free bacteria when mixed with cultures or adherent bacteria (Figures 5A and C). ${ }^{53-55}$ Furthermore, SWNTs exhibited a greater inactivation percentage, as demonstrated by decreased viability and metabolic activity, under both conditions..$^{53,54}$ To explain this observation, gene expression of $E$. coli during exposure to the nanotubes was studied; it was found that stress-related gene products were especially high in the presence of SWNTs, leading to the conclusion that the diameter of nanotubes determined the amount of stress and damage caused to the bacteria (MWNTs have larger diameters than SWNTs; see Figures 5B and D for a comparison of $E$. coli morphology on the two surfaces). ${ }^{53}$

The design of orthopedic implant materials for reducing infection could also benefit from the application of nanotechnology. In one study by Gabriel et al, it was found that when $\mathrm{ZnO}$ and $\mathrm{TiO}_{2}$ nanoparticles were pressed into compacts using a cold compaction method, a significant reduction in microbial adhesion was achieved compared with compacts composed of larger micron-sized particles (conventional sizes) of the same respective materials. ${ }^{49}$ This study found that $\mathrm{ZnO}$ nanoparticle compacts had the greatest antimicrobial behavior, probably due to the release of zinc (an antimicrobial metal ion). ${ }^{49}$ These findings 

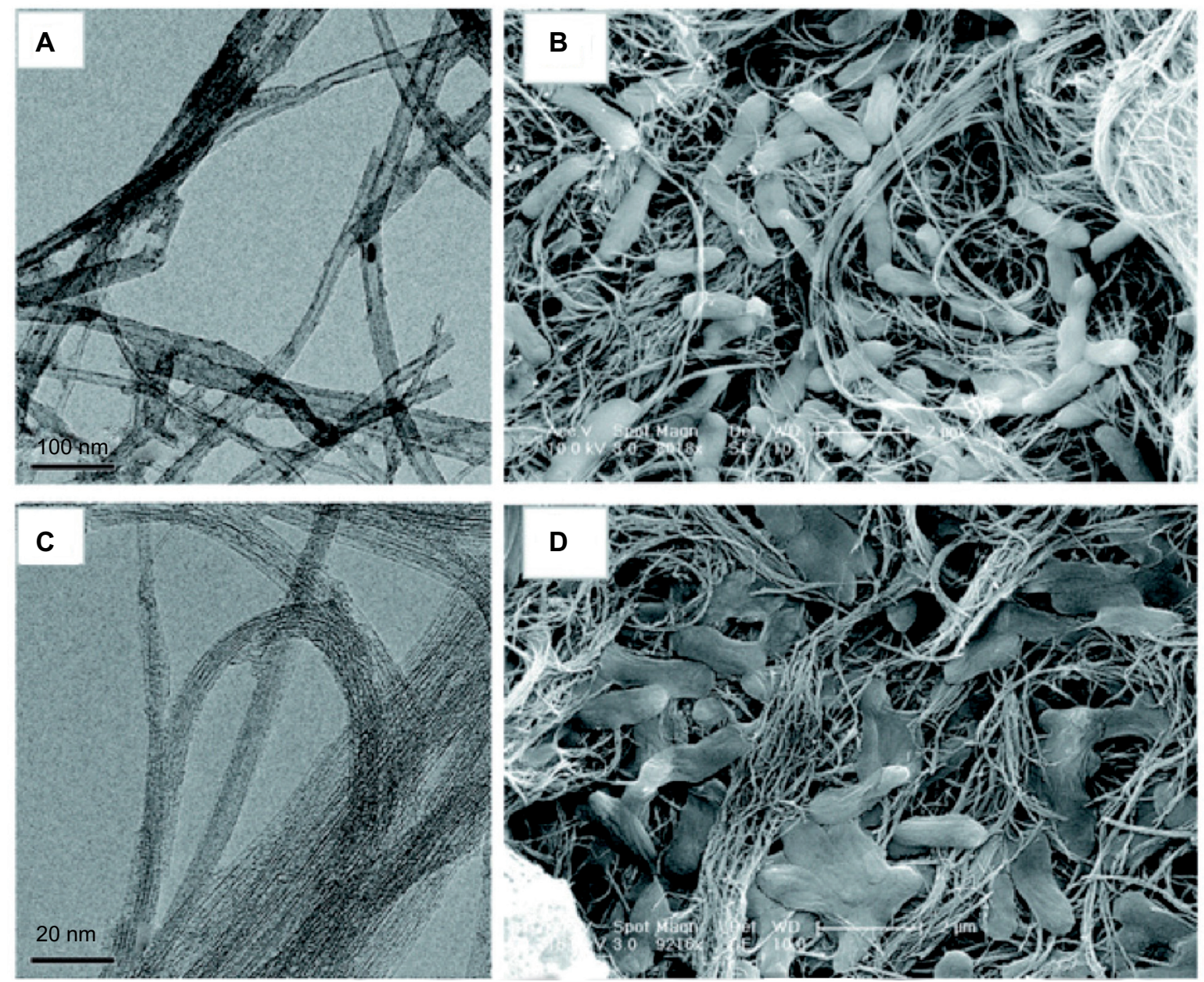

Figure $\mathbf{5}$ The diameter of the carbon nanotubes determined by transmission electron microscopy $(\mathbf{A}$ and $\mathbf{C})$ predicts antimicrobial behavior as visible in scanning electron micrographs (B and $\mathbf{D}){ }^{53}$ A mat-like surface made of multiwalled carbon nanotubes $(\mathbf{A})$ inactivates a small percentage of Escherichia coli, visible as abnormal and flattened bacteria on the surface (B). Single-walled carbon nanotubes (C), having a smaller diameter, inactivate a greater percentage of bacteria, causing significant structural disruption and bacterial death (D).

Note: Reprinted with permission from Kang S, Mauter MS, Elimelech M. Microbial cytotoxicity of carbon-based nanomaterials: implications for river water and wastewater effluent. Environ Sci Technol. 2009;43(7):2648-2653. Copyright 2009 American Chemical Society.

were compounded by the simultaneous finding that osteoblast (bone-forming cell) functions were significantly enhanced on the nanoparticle compacts for both materials when compared with their conventional counterparts. ${ }^{49}$

Another study by Puckett et al found that the antimicrobial properties of conventional titanium used in orthopedics could be enhanced through a simple nanosurface modification technique called "electron beam evaporation," which evaporates $\mathrm{TiO}_{2}$ using a high-energy electron beam, and allows the material to form on any titanium (Ti) surface; such surfaces were termed "nanorough." ${ }^{48}$ Other Ti nanosurface features were created through a process called anodization, an electrochemical etching process, to create nanotubular $\mathrm{Ti}$ and nanotextured $\mathrm{Ti}^{4}{ }^{48}$ Using bacteria live/dead staining, it was found that the nanorough surfaces reduced bacteria adhesion more than conventional Ti (live plus dead), while nanotubular and nanotextured Ti killed more bacteria (percentage of live and dead) ${ }^{48}$ It was concluded that surface fluorine, increased the adhesion of all bacteria on the anodized nanosurfaces and increased nanoroughness, resulting in higher surface energy, material crystallinity, and increased protein adsorption, which controlled bacterial adhesion on select nanofabricated surfaces. ${ }^{48}$ Because similarly fabricated nanosurfaces also enhanced other cell functions, such as skin-forming cells (keratinocytes) and osteoblasts, as found in other studies, ${ }^{56,57}$ it was concluded that Ti surfaces nanomodified by electron beam evaporation have a strong potential in the future design of more effective orthopedic or transcutaneous implant materials. ${ }^{48}$

Similarly, self-cleaning surfaces based on nanomaterials are already making a significant impact as antimicrobial paints for buildings and hospitals. One of the most popular self-cleaning coatings is based on UV light-activated photocatalytic $\mathrm{TiO}_{2}$ thin-films, the antimicrobial properties of which have been understood for over a decade. ${ }^{58}$ Yet, it is only recently, through 
the application of nanotechnology and enhanced optical properties, that the production of antimicrobial coatings activated in visible light (such as by fluorescent light bulbs) has become possible. In a study by Caballero et al, it was found that by including $\mathrm{TiO}_{2}$ nanoparticles in a paint formulation, bacteria were inactivated in the presence of fluorescent lighting alone. ${ }^{59}$ Antimicrobial paints used indoors (such as inside a hospital) have also been formulated through the application of silver nanoparticles. One such technology uses the natural oxidative drying process of vegetable oil to reduce silver into silver nanoparticles creating a nontoxic paint that can be used to coat wood, glass, steel, and various polymers, with strong activity against both gram-positive ( $S$. aureus) and gram-negative (E. coli) bacteria (Figure 6) while releasing silver slowly to increase the longevity of the antimicrobial activity. ${ }^{60}$

\section{Environmental and health considerations}

Lastly, as this review details, although there has been much promise for the use of nanomaterials (whether nanoparticles or nanostructured surface features) to fight infection, it would be remiss not to mention the possible, yet largely unknown, environmental consequences of nanomaterials. In particular, recent research has exposed the possible environmental and toxicological concerns of nanomaterials. This is especially true when considering that nanotechnology was estimated in 2008 to be a US\$10.5 billion industry in the USA (eg, through the use of nanotechnology in sunscreens, paints, and antimicrobial agents) that is expected to grow to 1 trillion by $2015 .^{61,62}$ Therefore, concerns about the accidental release of nanomaterials (during manufacturing or use) into the environment are growing.

Concerns have also been raised about damage to naturally occurring bacteria in the environment. For example, a study by Kang et al examined the potential release of carbon-based nanomaterials (CBNs), determining that patterns of cytotoxicity occurred with SWNT inactivating Pseudomonas aeruginosa, E. coli, and S. epidermidis, but not Bacillus subtilis. ${ }^{54}$ High rates of inactivation were also found in wastewater effluent and river water, especially with SWNTs, implying that certain CBNs might reduce microbial activity and potentially decrease microbial diversity. ${ }^{54}$ In a similar type of study by Bradford et al, it was shown that silver nanoparticles in a model of river estuarine sediments did not reduce microbial diversity (as determined by genetic diversity). ${ }^{63}$ Yet, separate concerns about the environmental release of silver nanoparticles have been raised, such as the potential spread of silver resistance in bacteria. ${ }^{64,65}$ Studies like these also help raise our awareness about the use of nanomaterials in humans for medical purposes, where microbial diversity (of natural microbial flora, which prevents the spread of virulent organisms) and resistance to nanomaterials (similar to current problems of antibiotic resistance) are of paramount concern.

In the area of prevention and treatment of infection, it has been proposed that materials not only be used by

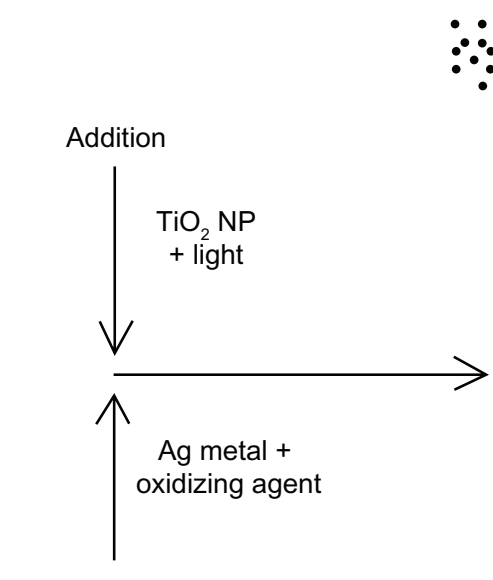

In situ synthesis

\section{$\because \because$ Nanoparticles (NP)}

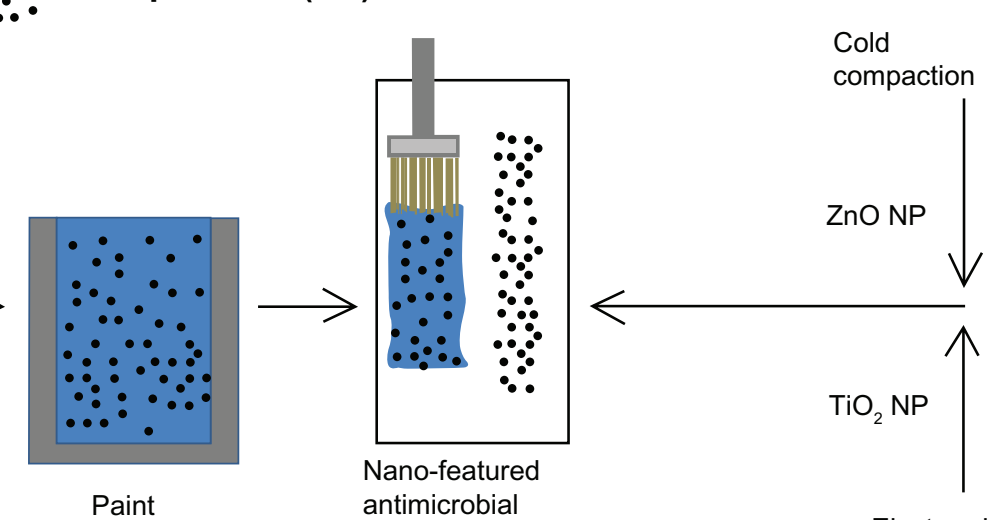

Electron-beam evaporation

Figure 6 Processes for the creation of nano-featured antimicrobial surfaces using addition, ${ }^{59}$ in situ synthesis, ${ }^{60}$ cold compation, ${ }^{49}$ or electron-beam evaporation ${ }^{48}$ incorporating nanoparticles. During addition, nanoparticles are simply added to the paint and, in the case of $\mathrm{TiO}_{2}$ nanoparticles, are activated using a light source, such as a fluorescent light. ${ }^{59}$ In situ synthesis uses the properties of the paint to reduce silver (Ag) metal into nanoparticles, for example using a metal-catalyzed free-radical-mediated oxidation process during the production of silver nanoparticles in vegetable oil-based paints. ${ }^{60}$ During cold compaction, nanoparticles are pressurized into a nano-featured surface, as previously achieved using a simple uniaxial, single-ended compacting hydraulic press held at $275 \mathrm{MPa}$ for 30 seconds, then held at a final pressure of $550 \mathrm{MPa}$ for I minute before releasing the pressure completely. ${ }^{49}$ Electron-beam evaporation concentrates a large amount of heat produced by high-energy electron-beam bombardment on the source material to be deposited, in this case pure Ti pellets, whereby heating and vaporization occur. ${ }^{48}$ The vapor flow then condenses onto the substrate surface located at the top of the vacuum chamber to control nano-featured or larger surface-feature creation. ${ }^{48}$ 
professionals (such as during infection treatment by clinicians in hospitals) but also by every person (such as nanoparticles in paints for use at home or over the counter nanodrugs). For this reason, future work must rely on collaboration among engineers, clinicians, and environmental scientists (and those from other fields as well) to fully characterize such nanomaterials in terms of chemistry, impurities, and toxicity. With the establishment of safe usage guidelines, nanomaterials can be safely used for the important and growing area of antibacterial material design. We should be excited (not frightened) about what the future holds for nanotechnology in these collaborative anti-infection efforts.

\section{Acknowledgments}

We would like to thank Dr Keiko Tarquinio for insightful comments and Mr Nathan Rubien for providing the biofilm scanning electron microscopy image (Figure 1B).

\section{Disclosure}

The authors declare no conflicts of interest in relation to this paper.

\section{References}

1. Cardo D, Horan T, Andrus M, et al. National Nosocomial Infections Surveillance (NNIS) System Report, data summary from January 1992 through June 2004, issued October 2004. Am J Infect Control. 2004;32(8):470-485.

2. O'Grady NP, Alexander M, Dellinger EP, et al. Guidelines for the prevention of intravascular catheter-related infections. Centers for Disease Control and Prevention. MMWR Recomm Rep. 2002;51(RR-10):1-29.

3. Rello J, Ochagavia A, Sabanes E, et al. Evaluation of outcome of intravenous catheter-related infections in critically ill patients. Am J Respir Crit Care Med. 2000;162(3):1027-1030.

4. Dimick JB, Pelz RK, Consunji R, Swoboda SM, Hendrix CW, Lipsett PA. Increased resource use associated with catheter-related bloodstream infection in the surgical intensive care unit. Arch Surg. 2001;136(2):229-234.

5. Mermel LA. Prevention of intravascular catheter-related infections. Ann Intern Med. 2000;132(5):391-402.

6. Stanton T, Haas J, Phillips M, Immerman I. Study points to savings with infection-screening program before TJR. AAOS Now 2010. Available from: http://www.aaos.org/news/aaosnow/mar10/clinical10.asp. Accessed 1 June 2011.

7. Bozic K, Kurtz S, Lau E, et al. The epidemiology of revision total knee arthroplasty in the United States. Clin Orthop Relat Res. 2010;468(1):45-51.

8. Bozic KJ, Kurtz SM, Lau E, Ong K, Vail TP, Berry DJ. The epidemiology of revision total hip arthroplasty in the United States. J Bone Joint Surg Am. 2009;91A(1):128-133.

9. Donlan RM. Biofilms and device-associated infections. Emerg Infect Dis. 2001;7(2):277-281.

10. Izano EA, Amarante MA, Kher WB, Kaplan JB. Differential roles of poly-N-acetylglucosamine surface polysaccharide and extracellular DNA in Staphylococcus aureus and Staphylococcus epidermidis biofilms. Appl Environ Microbiol. 2008;74(2):470-476.
11. Rohde H, Burandt EC, Siemssen N, et al. Polysaccharide intercellular adhesin or protein factors in biofilm accumulation of Staphylococcus epidermidis and Staphylococcus aureus isolated from prosthetic hip and knee joint infections. Biomaterials. 2007;28(9):1711-1720.

12. Hall-Stoodley L, Costerton JW, Stoodley P. Bacterial biofilms: from the natural environment to infectious diseases. Nat Rev Micro. 2004;2(2):95-108.

13. Gottlieb T, Atkins BL, Shaw DR. Infectious diseases - 7: soft tissue, bone and joint infections. Med J Aust. 2002;176(12):609-615.

14. Klein E, Smith DL, Laxminarayan R. Hospitalizations and deaths caused by methicillin-resistant Staphylococcus aureus, United States, 1999-2005. Emerg Infect Dis. 2007;13(12):1840-1846.

15. Hidron AI, Edwards JR, Patel J, et al. Antimicrobial-resistant pathogens associated with healthcare-associated infections: annual summary of data reported to the National Healthcare Safety Network at the Centers for Disease Control and Prevention, 2006-2007. Infect Control Hosp Epidemiol. 2008;29(11):996-1011.

16. Rosenthal VD, Maki DG, Jamulitrat S, et al. International Nosocomial Infection Control Consortium (INICC) report, data summary for 2003-2008, issued June 2009. Am J Infect Control. 2010;38(2):95-104.e2.

17. Neu HC. The crisis in antibiotic resistance. Science. 1992;257(5073): 1064-1073.

18. French GL. The continuing crisis in antibiotic resistance. Int $J$ Antimicrob Agents. 2010;36(Suppl 3):S3-S7.

19. Sanglard D, Odds FC. Resistance of Candida species to antifungal agents: molecular mechanisms and clinical consequences. Lancet Infect Dis. 2002;2(2):73-85.

20. Jabra-Rizk MA, Falkler WA, Meiller TF. Fungal biofilms and drug resistance. Emerg Infect Dis. 2004;10(1):14-19.

21. Pfaller MA, Diekema DJ, Gibbs DL, et al. Candida krusei, a multidrugresistant opportunistic fungal pathogen: geographic and temporal trends from the ARTEMIS DISK Antifungal Surveillance Program, 2001 to 2005. J Clin Microbiol. 2008;46(2):515-521.

22. Zhang L, Jiang Y, Ding Y, Povey M, York D. Investigation into the antibacterial behaviour of suspensions of $\mathrm{ZnO}$ nanoparticles (ZnO nanofluids). J Nanoparticle Res. 2007;9(3):479-489.

23. Arbab AS, Wilson LB, Ashari P, Jordan EK, Lewis BK, Frank JA. A model of lysosomal metabolism of dextran coated superparamagnetic iron oxide (SPIO) nanoparticles: implications for cellular magnetic resonance imaging. NMR Biomed. 2005;18(6):383-389.

24. Baker C, Pradhan A, Pakstis L, Pochan DJ, Shah SI. Synthesis and antibacterial properties of silver nanoparticles. J Nanosci Nanotechnol. 2005;5(2):244-249.

25. Ellis JR. The many roles of silver in infection prevention. Am J Infect Control. 2007;35(5):E26-E26.

26. Makhluf S, Dror R, Nitzan Y, Abramovich Y, Jelinek R, Gedanken A. Microwave-assisted synthesis of nanocrystalline $\mathrm{MgO}$ and its use as a bacteriocide. Adv Funct Mater. 2005;15(10):1708-1715.

27. Taylor EN, Webster TJ. The use of superparamagnetic nanoparticles for prosthetic biofilm prevention. Int J Nanomed. 2009;4:145-152.

28. Raghupathi KR, Koodali RT, Manna AC. Size-dependent bacterial growth inhibition and mechanism of antibacterial activity of zinc oxide nanoparticles. Langmuir. 2011;27(7):4020-4028.

29. Maki DG. Coming to grips with foodborne infection - peanut butter, peppers, and nationwide salmonella outbreaks. $N$ Engl J Med. 2009;360(10):949-953.

30. Sawai J, Kawada E, Kanou F, et al. Detection of active oxygen generated from ceramic powders having antibacterial activity. J Chem Eng Jpn. 1996;29(4):627-633.

31. Jones N, Ray B, Ranjit KT, Manna AC. Antibacterial activity of $\mathrm{ZnO}$ nanoparticle suspensions on a broad spectrum of microorganisms. FEMS Microbiol Lett. 2008;279(1):71-76.

32. Touati D. Iron and oxidative stress in bacteria. Arch Biochem Biophys. 2000;373(1):1-6.

33. Weinberg ED. Iron loading and disease surveillance. Emerg Infect Dis. 1999;5(3):346-352. 
34. Lipovsky A, Tzitrinovich Z, Friedmann H, Applerot G, Gedanken A, Lubart R. EPR study of visible light-induced ROS generation by nanoparticles of ZnO. J Physical Chem C. 2009;113(36):15997-16001.

35. Sawai J, Kojima H, Igarashi H, et al. Escherichia coli damage by ceramic powder slurries. J Chem Eng Jpn. 1997;30(6):1034-1039.

36. Sawai J, Shoji S, Igarashi H, et al. Hydrogen peroxide as an antibacterial factor in zinc oxide powder slurry. J Ferment Bioeng. 1998; 86(5):521-522.

37. Gu H, Ho PL, Tong E, Wang L, Xu B. Presenting vancomycin on nanoparticles to enhance antimicrobial activities. Nano Letters. 2003;3(9):1261-1263.

38. Mohammed Fayaz A, Girilal M, Mahdy SA, Somsundar SS, Venkatesan R, Kalaichelvan PT. Vancomycin bound biogenic gold nanoparticles: a different perspective for development of anti VRSA agents. Process Biochemistry. 2011;46(3):636-641.

39. Xing BG, Ho PL, Yu CW, Chow KH, Gu HW, Xu B. Self-assembled multivalent vancomycin on cell surfaces against vancomycin-resistant enterococci (VRE). Chem Commun. 2003(17):2224-2225.

40. Suci PA, Berglund DL, Liepold L, et al. High-density targeting of a viral multifunctional nanoplatform to a pathogenic, biofilm-forming bacterium. Chem Biol. 2007;14(4):387-398.

41. Liu L, Xu K, Wang H, et al. Self-assembled cationic peptide nanoparticles as an efficient antimicrobial agent. Nat Nano. 2009;4(7): 457-463.

42. Gao J, Gu H, Xu B. Multifunctional magnetic nanoparticles: design, synthesis, and biomedical applications. Acc Chem Res. 2009; 42(8):1097-1107.

43. Tran N, Webster TJ. Magnetic nanoparticles: biomedical applications and challenges. J Mater Chem. 2010;20(40):8760-8767.

44. Frey NA, Peng S, Cheng K, Sun SH. Magnetic nanoparticles: synthesis, functionalization, and applications in bioimaging and magnetic energy storage. Chem Soc Rev. 2009;38(9):2532-2542.

45. Chertok B, Moffat BA, David AE, et al. Iron oxide nanoparticles as a drug delivery vehicle for MRI monitored magnetic targeting of brain tumors. Biomaterials. 2008;29(4):487-496.

46. Oh J, Feldman MD, Kim J, Condit C, Emelianov S, Milner TE. Detection of magnetic nanoparticles in tissue using magneto-motive ultrasound. Nanotechnology. 2006;17(16):4183-4190.

47. Zhang L, Webster TJ. Nanotechnology and nanomaterials: promises for improved tissue regeneration. Nano Today. 2009;4(1):66-80.

48. Puckett SD, Taylor E, Raimondo T, Webster TJ. The relationship between the nanostructure of titanium surfaces and bacterial attachment. Biomaterials. 2010;31(4):706-713.

49. Colon G, Ward BC, Webster TJ. Increased osteoblast and decreased Staphylococcus epidermidis functions on nanophase $\mathrm{ZnO}$ and $\mathrm{TiO} 2$. J Biomed Mater Res Part A. 2006;78A(3):595-604.

50. Sinha N, Yeow JTW. Carbon nanotubes for biomedical applications. IEEE Trans. Nanobiosci. 2005;4(2):180-195.
51. Webster TJ, Waid MC, McKenzie JL, Price RL, Ejiofor JU Nano-biotechnology: carbon nanofibres as improved neural and orthopaedic implants. Nanotechnology. 2004;15(1):48-54.

52. Sirivisoot S, Pareta R, Webster TJ. Electrically controlled drug release from nanostructured polypyrrole coated on titanium. Nanotechnology. 2011;22(8):085101.

53. Kang S, Herzberg M, Rodrigues DF, Elimelech M. Antibacterial effects of carbon nanotubes: size does matter! Langmuir. 2008;24(13):6409-6413.

54. Kang S, Mauter MS, Elimelech M. Microbial cytotoxicity of carbonbased nanomaterials: implications for river water and wastewater effluent. Environ Sci Technol. 2009;43(7):2648-2653.

55. Kang S, Pinault M, Pfefferle LD, Elimelech M. Single-walled carbon nanotubes exhibit strong antimicrobial activity. Langmuir. 2007;23(17):8670-8673.

56. Puckett SD, Lee PP, Ciombor DM, Aaron RK, Webster TJ. Nanotextured titanium surfaces for enhancing skin growth on transcutaneous osseointegrated devices. Acta Biomaterialia. 2010;6(6): 2352-2362.

57. Puckett S, Pareta R, Webster TJ. Nano rough micron patterned titanium for directing osteoblast morphology and adhesion. Int J Nanomed. 2008;3(2):229-241.

58. Sunada K, Kikuchi Y, Hashimoto K, Fujishima A. Bactericidal and detoxification effects of $\mathrm{TiO} 2$ thin film photocatalysts. Environ Sci Technol. 1998;32(5):726-728.

59. Caballero L, Whitehead KA, Allen NS, Verran J. Photoinactivation of Escherichia coli on acrylic paint formulations using fluorescent light. Dyes Pigments. 2010;86(1):56-62.

60. Kumar A, Vemula PK, Ajayan PM, John G. Silver-nanoparticle-embedded antimicrobial paints based on vegetable oil. Nat Mater. 2008;7(3): 236-241.

61. Aitken RJ, Chaudhry MQ, Boxall ABA, Hull M. Manufacture and use of nanomaterials: current status in the UK and global trends. Occup Med Oxf. 2006;56(5):300-306.

62. Handy RD, von der Kammer F, Lead JR, Hassellov M, Owen R, Crane M. The ecotoxicology and chemistry of manufactured nanoparticles. Ecotoxicology. 2008;17(4):287-314.

63. Bradford A, Handy RD, Readman JW, Atfield A, Mühling M. Impact of silver nanoparticle contamination on the genetic diversity of natural bacterial assemblages in estuarine sediments. Environ Sci Technol. 2009;43(12):4530-4536.

64. Gupta A, Silver S. Molecular genetics - silver as a biocide: will resistance become a problem? Nat Biotechnol. 1998;16(10):888.

65. Chopra I. The increasing use of silver-based products as antimicrobial agents: a useful development or a cause for concern? J Antimicrob Chemother. 2007;59(4):587-590.

66. Otto M. Staphylococcus epidermidis - the 'accidental' pathogen. Nat Rev Micro. 2009;7(8):555-567.
International Journal of Nanomedicine

\section{Publish your work in this journal}

The International Journal of Nanomedicine is an international, peerreviewed journal focusing on the application of nanotechnology in diagnostics, therapeutics, and drug delivery systems throughou the biomedical field. This journal is indexed on PubMed Central,

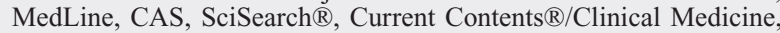

\section{Dovepress}

Journal Citation Reports/Science Edition, EMBase, Scopus and the Elsevier Bibliographic databases. The manuscript management system is completely online and includes a very quick and fair peer-review system, which is all easy to use. Visit http://www.dovepress.com/ testimonials.php to read real quotes from published authors. 